\title{
HERMENEUTIK
} DES

\section{ALTEN TESTAMENTS}

\section{MIT SPEZIELLER BERÜCKSICHTIGUNG DER MODERNEN PROBLEME}

\author{
VON
}

\section{EDUARD KÖNIG}

DR. LITT. SEMIT., PHIL. THEOL.,

ORDENTLICHEM PROFESSOR UND GEHEIMENI KONSISTORIALRAT IN BONN

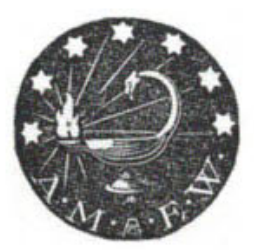

BONN 1916

A. MARCUS \& E. WEBERS VERLAG 
Alle Rechte, insbesondere das der Übersetzung, vorbehalteu. Copyright 1916 by A. Marcus \& E. Webers Verlag, Bonn. 


\section{Meiner lieben Frau,}

der trenen Helferin bei der Korrektur meiner Arbeiten, gewidmet! 
